\title{
Grade 10 ENGLISH FirST ADDITIONAL LANGUAGE LEARNERS' STRATEgies FOR PAST SimPle TENSE IRREgUlar VERBS INFLECTION MASTERY
}

\author{
Farisani Thomas Nephawe ${ }^{1)}$, Matodzi Nancy Lambani ${ }^{2)}$ \\ 1) University of Venda, South Africa \\ E-mail: Farisani.nephawe@univen.ac.za \\ 2) University of Venda, South Africa \\ E-mail: Matodzi.lambani@univen.ac.za
}

\begin{abstract}
The mastery of the irregular form of verbs in the past simple tense poses challenges to non-native learners of English all over the world. The objectives of this research paper were to establish why the English First Additional Language learners face difficulties in mastering the inflection of irregular verbs in the past simple tense, and identify strategies useful for mastering the inflection of the irregular verbs. The research paper adopted a quantitative research design. A questionnaire was used as an instrument for data collection from the respondents. Data were analysed using the Statistical Package for Social Sciences version 22 to ensure valid interpretations. Date were presented in a table and a graph dealing with the inflection of irregular verbs in the past simple tense. The respondets of this research paper comprised 21 Grade 10 learners of Dimani Secondary School in Limpopo Province, South Africa in the 2021 academic year. Initially, the respondents experienced difficulties in using the suppletion principle and the terminal consonants phoneme changes. Therefore, the researchers used two irregular verbs learning strategies, namely: the grouping of common irregular verbs and the learning of irregular verbs in sentences to enhance the learners'mastery of the irregular verbs inflection. The findings revealed that learners had improved significantly in the mastery of irregular verbs inflection in the past simple tense after utilising these two strategies.
\end{abstract}

Keywords: Inflection; irregular verbs; past simple tense; Strategies

\section{INTRODUCTION}

The learning of irregular verbs inflection in the past simple tense poses difficulties to the English First Additional Language (EFAL) learners because there are numerous verbs which are formed irregularly. Irregular verbs in the past simple tense do not have a pattern regarding past tense verb formation. The inflection system does not add the -ed ending to the root of verbs (Zaia, 2015; Author, 2019) or past participle forms even though it does with the regular verbs through adding the -ed ending to the root of verbs. However, the sound patterning of verbs is used for marking the past simple tense, and so are the perfect tenses in English. The difference in sound patterning between regular and irregular verbs depends on the pattern of verb formation. Therefore, the formation of past tense irregularisation of verbs does not follow the same phonological patterns as that of regular verbs because the morphemes are unpredictable.

The EFAL learners confuse the inflection of the irregular verbs in the past simple tense for the regular ones, in this regard. The unpredictability of irregular verbs inflection in the past simple tense creates difficulties for these learners when they form irregular verbs in the past simple tense. Although a few patterns can be learnt, one might eventually need to work on memorising each form of an irregular verb. However, memorising the inflection of irregular verbs in the past simple tense is not an easy task especially for nonnative learners of English. Even if these learners started learning English from Grade 4, the National Curriculum Statement Grades 10 - 12 (2012) emphasises that they are incompetent in the inflection of irregular verbs in the past simple tense. The assumption is that by the time these learners progress from Senior Phase to Further Education and Training Band, they must be competent enough in the inflection of irregular verbs. Nevertheless, they still experience challenges regarding the inflection of irregular form of verbs (Odetallah, 2013) in the past simple tense. Considering this challenge, there is a need, therefore, to provide learners with suitable strategies to enhance the mastery of irregular verbs inflections in the past tense.

According to Rosydah (2018), second language (L2) learners, commit two frequent errors such as adding wrong suffix '-ed' to the irregular verbs and produce deviant 
structures, for instance, break/*breaked and go/*goed. When these learners realise that they cannot differentiate between the regular and irregular verbs, they seek refuge in the inflection of regular ones and consequently commit errors. In learning the inflection of irregular verbs in the past simple tense, they start by acquiring them in chunks, for example, broke, woke, or no past form at all. The suggestion is that the acquisition of irregular verbs in the past simple tense is a difficult process for the learners whose mother-tongue is not English. The difficulties faced by these learners are exacerbated by the fact that there is no rule regarding the inflection of an irregular form of verbs in their home languages (Rosydah, 2018), and that irregular verbs in the past simple tense change the forms based on the time of action. Moreover, these learners overgeneralise rules of the inflection of irregular verbs in the past simple tense. Nevertheless, even if the EFAL learners have learnt English for six years, in Grade 10 they still face difficulties in the inflection of irregular verbs in the past simple tense. Notwithstanding, the provision of irregular verb lists in numerous English language textbooks (Idek \& Fong, 2015). These verbs obtain their past forms when vowels are changed or left unchanged, for example, 'begin/began' and spread/spread'. In the process, learners use deviant inflection of the irregular verbs in the past simple tense. Due to their inconsistent manner of changing from the present tense to the past tense forms (Rosydah, 2018), irregular verbs may prove difficult to memorise. One reason for the difficulties in learning irregular verbs is that there are approximately 180 of them in English (Deibler, 2012) and can be created differently, for example, seek/sought. However, learners cannot memorise all irregular verbs within a short space of time and recognise their past simple forms or the past participle forms.

In respect of the inflection of irregular verbs in the past simple tense, Rahmawati (2019) and Author (2019) studied the inflection of irregular verbs by the high school learners and discovered that they faced difficulties when attempting to memorise them. The findings indicate that the students studying English at institutions of higher learning such as colleges and universities also face difficulties in the inflection of irregular verbs in the past tense. The study by Naser (2017) demonstrates that the use of irregular verbs inflection by university students is problematic as $75 \%$ of them could not use irregular verbs correctly. In addition, Majeed (2018) investigated irregular morpheme errors among university students and found that their performance was unsatisfactory. Furthermore, Mouri (2020) studied firstyear university students and found recurrent errors in the mastery of irregular verbs in the past simple tense. Nonetheless, Majeed (2018) and Mouri (2020) were incongruent in thinking that some strategies cannot improve the learners' mastery of irregular verbs inflection in the past tense. In essence, the Grade 10 EFAL learners are equally affected by the challenges in this regard.

\section{Theoretical Framework}

The research paper is underpinned by Petty, Cacioppo, Strathman, and Priester's (2005) dual-mechanism and Chomsky's (1965) grammatical competence theories.

Dual-mechanism theory: Petty, et al. (2005) postulate that in 'dual mechanism theory', the brain is a collection of identifiable regions. This theory states that in the brain there are specific regions developed to deal with language activities. For example, the 'main area' of the brain assesses language structures according to diverse rules and patterns consisting the regular and irregular forms of verbs in past simple tense. However, this theory speculates that the L2 learners master the inflection of regular verb rules much faster than irregular verbs. Still, it was not always the case that the inflection of regular verbs supersedes the irregular ones. The 'secondary associative memory area' of the brain interprets, classifies, and stores the irregular verbs, according to the order in which they belong. However, if this area can perform these activities accordingly, the L2 learners would not face difficulties in the inflection of irregular verbs in the past simple tense. During the time at which learners must select the suitable past simple tense form of the English verb, a comparison of the word is made with the familiar exceptions. In this process, the matching irrational form of the verb is considered if it is available in the brain (Deibler, 2012). Nonetheless, if it is difficult to find, the regular past simple tense verb form is created by adding the '-ed' ending to the root of verbs to compensate for the uncertainties. Thus, it is worth noting that the over-regularisation of verbs might prevail to corroborate this theory.

Grammatical competence theory: This theory was propounded by Noam Chomsky in 1965, and he emphasises that a human being is born with innate and unconscious knowledge of language learning. In this situation, the L2 learners' inborn knowledge does not necessitate the English language. There are grammatical codes such as morphological, syntactic, semantic, phonetic, vocabulary, orthographic rules, and mechanics which enable the L2 learners to use and understand the target language (Nordquist, 2017). Therefore, the focus was on morphology and syntax because they are a prerequisite (Canale \& Swain, 1980) for effective inflection of irregular verbs in the past simple tense. These grammatical codes enable learners to understand the inflection, in this case, the irregular verbs in the past tense, hence communicative competence theory particularly grammatical competence is a prerequisite for appropriate communication in the English language.

\section{Strategies For Learning Past Simple Tense Irregular Verbs}

There are numerous strategies for mastering irregular verbs inflection in English including grouping common irregular verbs, turning memorisation into a game (Rundell, 2014; Atlas Language School, 2020), memorising the 10 most common irregular verbs first, asking learners to correct one another, leaving the lists of irregular verbs where learners can see them, learning of all new vocabulary with the tense form and learning of irregular verbs in sentences. However, in this research paper, the focus was on 'grouping 
common irregular verbs together' (engVid, 2021), and the 'learning of irregular verbs in sentences' (Author, 2019). The researchers used these two strategies because learners have different capabilities of learning irregular verbs in the past simple tense. In their first attempt to find out learners' competence in the inflection of the irregular verbs in the past simple tense, the researchers discovered that learners performed below average. However, it was worth noting that after having used the two targeted strategies for learning verb inflection, in the past simple tense, it has been revealed that learners' performance was satisfactory.

Grouping common irregular verbs: In this strategy, both past simple tense form and the past participle form of verbs were included to indicate the inconsistency of irregular verb formation. Although there are several irregular verbs in the past simple tense, the researchers considered 'suppletion' and 'terminal consonants phoneme changes' as representatives of all irregular verbs existing in English due to the limited scope of this research paper. The researchers used verb stems in the present simple tense form, the past simple tense form, and the past participle form of verbs and their examples to illustrate how irregular verbs are formed. The following tables, therefore, contain irregular verbs in the 'suppletion principle', and the 'terminal consonants phoneme changes:

TABLE I

IRREGULAR VERBS: SUPPLETION

\begin{tabular}{llll}
\hline No & Verb stem & Simple past & Past participle \\
\hline 1. & Go & Went & Gone \\
2. & Is/Am (be) & Was & Been \\
3. & Are (be) & Were & Been \\
\hline
\end{tabular}

TABLE II

\begin{tabular}{llll}
\multicolumn{4}{l}{ IRREGULAR VERBS: TERMINAL CONSONANTS } \\
\hline No & Verb stem & Simple past & Past participle \\
\hline 1. & Bring & Brought & Brought \\
2. & Begin & Began & Begun \\
3. & Fling & Flung & Flung \\
4. & Sleep & Slept & Slept \\
5. & Strive & Strove & Striven \\
6. & Win & Won & Won \\
\hline
\end{tabular}

learning of irregular verbs in sentences: In this strategy, the Grade 10 EFAL learners can master irregular verbs appropriately, especially if short sentences are utilised because they are easy to comprehend. In sentences such as 'We get money today, we got the money yesterday and 'You seek permission now but you sought for it last week'. Therefore, using the strategy, namely: the learning of irregular verbs in sentences can enhance the mastery of the inflection of the irregular verbs in the past simple tense. In this instance, learners enjoy learning particular rhythmic sentences than long strings of tedious ones.

\section{Modification of Irregular Verbs in Past Simple Tense}

Irregular verb modification in past simple tense occurs in several forms with no consistent patterns. According to the
Author (2019), these conditions include the 'suppletion principle', the 'ablaut principle', the 'terminal consonants phoneme changes', and the 'zero-making principle'. However, the focus of this research paper was the use of strategies to master the 'suppletion principle' and the 'terminal consonants phoneme changes' as the two areas in which the majority of the L2 learners commit errors.

Suppletion principle: In this principle, the two strategies, namely: the 'grouping of the common irregular verbs', and the 'learning of irregular verbs in sentences' were utilised in learning the inflection of the irregular verbs in the past simple tense. The L2 learners were taught how to group the forms of irregular verb 'to be', namely: 'am', 'is', 'are', 'was', 'were' and 'been', etc. Also, they were informed that the irregular verb 'go' must be grouped with the verb 'to be' because it changes from the simple present tense to either the past simple or the past participle form of verbs. They were trained to place the common irregular verbs in tables to comply to the strategy of learning irregular verbs in groups. The researchers indiscriminately grouped the common irregular verbs according to the verb stems in present simple form, the past simple form, and the past particple form of verbs. They instructed them to group the irregular verbs in tables according to their time of action.

The root of the verbs changes into new forms because there is no regular phonological communication with other forms, for example, go/went. It includes the word forms of the same lexeme with phonologically distinct stems and entails the dissimilar allomorphs of the same morphemes i.e. it is associated with two phonologically unconnected realisations depending on the morphosyntactic context. Moreover, In this instance, it is accurate that when learners face difficulties in forming the past simple form of irregular verbs, they might reckon out their grammatical rules (Denham \& Lobeck, 2013). For example, a sentence such as *'They goed to the cinema' can be formed instead of 'They went to the cinema' even though syntax requires lexemes that cannot be morphologically predictable.

Furthermore, the strategy regarding the learning of irregular verbs in sentences was utilised. Learners were given short sentences that have good rhythm such as 'Today the lady goes home, yesterday she went home after everybody has gone from the cinema'. The researchers asked learners to repeat the sentence starting from the part to arouse their attention. For example, 'After everybody has gone from the cinema, the lady went home yesterday, but today she goes home'. All learners were requested to stand up in their classroom. The researchers selected learners randomly and requested them to repeat the sentence from the beginning. The learner could only sit down after having shown understanding of the answer, and then the sentence was passed on to the next learner who would start it from its last part. Learners who could not get the answers correctly remained standing, and could only sit down after having answered the sentence correctly. The researchers did the same with the other forms of the verb 'be' regardless of the tense under which they belonged. In this situation, learners got motivated and learnt the suppletion principle with ease. 
Therefore, they understood the 'suppletion rule principle' and realised that the entire stem go- must be replaced by the different stem 'went'. Hence, they could effect a total change in the irregular verb forms.

Terminal consonants phoneme changes: This mechanism entails the removal of one vowel from a word and the addition of the sound ' $-\mathrm{t}$ ' to the stem of the word such as keep/kept, and spell/spelt. The two strategies such as the 'grouping of the irregular verbs', and the 'learning of irregular verbs in sentences' were also involved in learning the 'terminal consonants phoneme changes'. Learners were shown how irregular verbs in the past simple tense can be grouped to ease their memorisation. Learners were given a task to rearrange the irregular verbs according to their order of appearance in each column relating to the 'grouping of irregular verbs' strategy. For example, they were instructed to group them according to their similarity in the second and the last column or different appearance in each column.

The 'grouping of irregular verbs' strategy necessitates the formation of irregular verbs in the past simple tense. The L2 learners were able to construct the sentence 'The fishbone *sticked in his false teeth' instead of 'The fishbone stuck in his false teeth'. According to the Author (2019), the irregular verbs can be changed from the present simple forms into the past ones using the addition of the final ' $-\mathrm{t}$ ', and the changing of the stem vowel from '-i' to '-e', for example, creep/crept, changing the vowel ' $\mathrm{i}$ ' to '-o', in think/thought, changing the vowel '-e' into '-o' in seek/thought. Therefore, learners' grammatical competence was enhanced.

Furthermore, learners were informed that the vowel ' $-\mathrm{i}$ ' can be transformed into '-u' in stick/stuck, and the doubling of the last consonants of the verbs before adding the suffix 'ed' to produce a similar word, for example, prefer/preferred. Learners'grammatical competence was also improved because they were able to place the irregular verbs accordingly in their respective columns. Therefore, the use of this strategy necessitates considerable proficiency in the inflection of irregular verbs in the past simple tense. This finding is in contrast with Author's (2019) claims that the inflectional morphology in the irregular past tense, in comparison with irregular inflections, creates difficulties for learners because of their complex irregularities. In this situation, the 'grouping of irregular verbs is an invaluable strategy for learning the 'terminal consonants phoneme changes' in the past simple tense.

Regarding the strategy for learning the inflection of irregular verbs concerning the 'terminal consonants phoneme changes', also the second language learners were given rhythmic short sentences to memorise verbs in this situation. For example, the researchers used the sentence: 'They win the prize now, they won the prize last year but they never wanted to share the prize they have won'. The researcher instructed learners to write the learnt past tense sentence into their exercise books to enhance their grammatical competence. Therefore, if learners could write the correct sentences, it is evident that the 'learning of irregular verbs in sentences' is an indispensable strategy for learning the 'terminal consonants phoneme changes'

\section{METHODS}

The research paper used Classroom Action Research (CAR) as a technique of getting detailed information from the respondents' participation in the research paper. The researchers and or the educational practitioners (Sutarti (2017) investigate the respondents in their natural settings to improve their teaching practices. The purpose of the CAR is to advance rationale and quality including (a) socioeducational training, (b) knowledge of the practice, (c) the milieu at which practice is done. It is designed to improve the quality of learners' competence in the topic under scrutiny. This model arouses learners' interest in educational perception.

In this research paper, the researchers used learners' interpretation of variables in each thematic attribute regarding the inflection of the irregular form verbs in the past simple tense. As all the learners came from villages, the possibility was that they could have shared similar exposure to the English language so much that the research paper focus can be easily identified (Creswell, 2014). The research was conducted at Dimani High School in Limpopo Province, South Africa. As simple random sampling (Bala, 2017) technique provided every member of the population a likelihood of participating in the sample. Since the overall population of the Grade 10 EFAL comprised 213 learners, 21 respondents were sampled according to the acceptable $10 \%$ sample population norm.

Empirical data were collected from the following points of view, namely: (1) the researchers' delivery of the questionnaire, (2) learners' reaction when responding to the questionnaire, and (3) the environment at which they responded to the questionnaire. The questionnaire comprises a list of questions, along with the choice of answers, printed or typed in a sequence to acquire specific information from the respondents (Aryal, 2017). The researchers, therefore, drafted closed-ended questions from which learners made their informed choices from a set of pre-defined responses. As a structured interview (Gazu, 2020), questions requiring 'yes', or 'no' answers can be asked, items on a list are checked, or answers from multiple-choice options are selected. Therefore, questions were placed on a table and a graph for learners to indicate their personal opinions in this research paper. Moreover, learners' written responses and observations made by the researchers ensured that learners responded carefully and honestly to the questionnaire. Thus, the validity and reliability of the CAR model were accomplished.

The quantitative research design was used because it is an "engine behind evidence-based outcomes" (Abuhamda, Bsharat \& Ismail, 2021:71). It uses statistical and mathematical techniques in exploring unfamiliar areas (Lediga \& Ngoepe, 2020), and the percentages of the variables translate into accurate results. Data were analysed using the Statistical Package for Social Sciences (SPSS) version 22. Miles and Huberman's model of data analysis were used. Their step-by-step model of analysis includes data reduction, data presentation, and making conclusions depicting research findings and verification of the research 
paper findings. Eventually, (1) data reduction was invaluable as it helped in sorting, selecting, classifying, and eliminating irrelevant data against the focus of the research paper, (2) the relevant data were interpreted and presented according to the aim of the research paper, and (3) conclusion was three-fold: the depiction of the research findings, verification of data, and specification and validation of the results that lead to the withdrawal of the conclusion of the research paper. The researchers then found the research paper findings that are specific and end on illustrating convincing conclusions.

\section{RESULTS AND DISCUSSIONS}

From the objective of identifying the types of strategies suitable for learning the inflection of irregular verbs in the past simple tense, the two strategies, namely: the 'grouping of common irregular verbs' and the 'learning of irregular verbs in sentences' provided reliable data to the researchers. This has been proved from the application of the two strategies in the 'suppletion principle' and the 'terminal consonants phoneme changes'. In the application, therefore, of these strategies, learners demonstrated considerable competence in the mastery of irregular verbs inflection in the past simple tense.

To ascertain the validity of the respondents' grammatical competence, in this regard, the researchers used a questionnaire concerning the application of the knowledge gained from the use of the two strategies. Five multiplechoice questions were provided within the brackets concerning the inflection of irregular verbs in the past simple tense. The strategies for learning the inflection of irregular verbs in the past simple tense regarding the 'suppletion principle' and the 'terminal consonants phoneme changes' were the foundation of the questionnaire. The respondents were requested to select the appropriate answer that could demonstrate their grammatical competence after they have been trained to use the two strategies for learning the inflection of irregular verbs in the past simple tense.

The researchers utilised a table showing the correct and the incorrect responses from the respondents regarding the choices provided in the table. Percentages were used to represent statistical data obtained from the respondents' grammatical competence in the inflection of irregular verbs in this regard. Therefore, the respondents' performance, was reduced to numbers as it can be seen in the next table.

TABLE III

TERminal CONSONANTS PHONEME CHANGES

\begin{tabular}{|c|c|c|}
\hline \multirow[t]{2}{*}{ Questions } & \multicolumn{2}{|c|}{$\begin{array}{l}\text { Respondents' } \\
\text { responses }\end{array}$} \\
\hline & $\begin{array}{l}\text { Correct } \\
\text { responses }\end{array}$ & $\begin{array}{l}\text { Incorrect } \\
\text { responses }\end{array}$ \\
\hline $\begin{array}{l}\text { 1) } \mathrm{He} \text { (seeked/sought) for } \\
\text { help from strangers last } \\
\text { night. }\end{array}$ & $83.6 \%$ & $16.4 \%$ \\
\hline $\begin{array}{l}\text { 2) They (brought/bringed) } \\
\text { the case before the court. }\end{array}$ & $72.7 \%$ & $27.3 \%$ \\
\hline
\end{tabular}

\begin{tabular}{|c|c|c|c|}
\hline & $\begin{array}{l}\text { She (kept/keeped) crying } \\
\text { for toys yesterday. }\end{array}$ & $58.6 \%$ & $41.4 \%$ \\
\hline & $\begin{array}{l}\text { The roughly thatched } \\
\text { house (catched/caught) } \\
\text { fire from the barbecued } \\
\text { meat. }\end{array}$ & $70.9 \%$ & $29.1 \%$ \\
\hline 5) & $\begin{array}{l}\text { We (built/builded) a big } \\
\text { lodge by the other side } \\
\text { of the river. }\end{array}$ & $64.3 \%$ & $35.7 \%$ \\
\hline
\end{tabular}

Question 1 shows that the majority $(83.6 \%)$ of the respondents were competent in the mastery of the past simple tense because they could use the strategies learnt for understanding the inflection of such irregular verbs. They became accustomed to the rule about the inflection of irregular verbs in this tense because they were trained to use strategies, namely: the grouping of the irregular verbs, and the learning of irregular verbs in sentences. The finding is incongruent with Rahmawati's (2019) suggestion that respondents face difficulty in the inflection of irregular verbs in the simple past tense. The respondents could recognise the correct form of the irregular verb 'sought' resulting from the changing of vowels from ' $\mathrm{e}$ ' to '-ou' in the question: 'He (seeks/sought) for help from strangers last night' when forming the irregular verb 'sought'.

Nevertheless, only $16.4 \%$ were incompetent (Naser, 2017) with the inflection of the past simple tense which stands to suggest that the strategies used were helpful. The respondents confused the rule regarding the inflection of irregular verbs in the past simple tense. The rule states that the ending '-ed' is added to the root of the regular verbs when forming the past simple tense. In this instance, learners selected the word *seeked for an answer.

Question 2 shows that the majority $(72.7 \%)$ of the respondents were competent in the question: 'They (brought/bringed) the case before the court', because they could apply the rule they had learnt from the two strategies, namely: the 'grouping of the irregular verbs', and the 'learning of irregular verbs in sentences'. The rule states that when forming the irregular verbs in the past simple tense, the vowels 'ou' can replace ' $i$ ' vowel that the remaining verb 'brought' is in line with the past simple tense form. The finding of this research paper was congruent with Rahmawati (2019) who suggested that there was a deficit in using irregular verbs.

However, $27.3 \%$ of the respondents were incompetent in the application of the two strategies they have learnt for the inflection of irregular verbs (Majeed, 2018) in the past simple tense. On this basis, these respondents might have been confounded by the rule regarding the inflection of the suffix '-ed' to the stem of verbs. Hence, they opted for the ungrammatical answer *'bringed' instead of 'brought'.

Question 3 reveals that $58.6 \%$ of the respondents could apply the strategies such as the 'grouping of the irregular verbs', and the 'learning of irregular verbs in sentences' they have learnt for the inflection of irregular verbs in the past simple tense in the question: 'She (kept/keeped) crying for 
toys yesterday'. They could distinguish between the irregular verb 'kept' and *'keeped' which is grammatically incorrect since they were aware that the double ' $\mathrm{e}$ ' vowels can be reduced into a single ' $\mathrm{e}$ ' vowel to form the past tense forms of verbs. The finding is dissimilar to Mouri's (2020) claim that learners could not form irregular verbs in the past simple tense. They knew that the verb ending '-ed' must not be indiscriminately added to the root of verbs.

It is a point of concern that almost $41.4 \%$ of the respondents were incompetent in the inflection of irregular verbs concerning the 'terminal consonants phoneme changes'. These respondents were unfamiliar with the rule regarding the formation of irregular verbs in the past simple tense because they selected the answer 'keeped' instead of 'kept'. Nonetheless, even though some respondents were not competent in the inflection of irregular verbs in the past simple tense, the majority of the respondents demonstrated their competence in this regard.

Question 4 shows that the majority (70.9\%) of the respondents were competent in the formation of the irregular verbs in the past simple tense concerning the question: 'The roughly thatched house (catched/caught) fire from barbecued meet'. They indicated their skill of applying the two strategies they have lear learnt for dealing with the 'terminal consonants phoneme changes', namely: the 'grouping of the irregular verbs', and the 'learning of irregular verbs in sentences'. These respondents showed proficiency in the inflection of the irregular verbs in the past simple tense because they selected the answer 'caught' and ignored *'catched' which is grammatically incorrect. They knew that the suffix '-ed' is not the only way of forming irregular verbs in the past simple tense because the vowel ' $a$ ' can be changed into 'au' to form the irregular verbs in the past simple tense. This finding is in contrast with Majeed's (2018) assertion that learners cannot form irregular verbs in this regard.

However, 29.1\% of the respondents were unaware (Mouri, 2020) of the rule relating to the infection of irregular verbs in the past simple tense. They did not know that the double 'e' vowels must be reduced to a single ' $\mathrm{e}$ ' vowel when dealing with the 'terminal consonants phoneme changes' in the past simple tense. They might have been confused by the rule relating to the addition of the suffix '-ed' to the stem of regular verbs. Therefore, the strategies for learning the irregular verbs in the past simple tense improved the respondents' performance even though the minority of them indicated poor competence in this essence.

Question 5 shows that the majority $(64.3 \%)$ of the respondents were competent in the application of the two strategies such as the 'grouping of the irregular verbs', and the 'learning of irregular verbs in sentences' for learning irregular verbs inflection. They could respond positively to the question: We (built/builded) a big lodge by the other side of the river' because they selected the answer 'built' and rejected 'builded' which is grammatically inappropriate. These respondents knew that the last consonant ' $d$ ' in the verb 'build' is transformed into ' $t$ ' when forming irregular verbs in the past simple tense because they understood the application of the two strategies in this regard. The finding is consistent with Rahmawati's (2019) claim that respondents can transform the last consonant of an irregular verb into the other consonant when forming the past simple form, and the past participle form of irregular verbs.

However, the minority $35.7 \%$ of the respondents were incompetent in the application of the two strategies they have learnt, namely: the 'grouping of the irregular verbs', and the 'learning of irregular verbs in sentences' for the inflection of the irregular verbs in the past simple tense (Naser, 2017). They were not aware that the word *'builded' is ungrammatical, and must not be used in forming the irregular form of verbs in the past simple tense. Therefore, they rejected the grammatically proper answer 'built' in favour of *'builded'. The respondents might have been confused by the rule regarding the addition of the '-ed' ending to the root of verbs during the inflection of irregular verbs in the past simple tense.

In adjusting the vowels and consonants from one form to another during the irregularisation of verbs based on the 'terminal consonants phoneme changes', most respondents demonstrated their competence in the inflection of the irregular verb both in the past simple tense form and the past participle form of verbs. Although the minority of the respondents were incompetent (Rahmawati, 2019), the research paper established that the majority of the respondents became competent in the inflection of irregular verbs in the past simple tense. Therefore, the respondents could demonstrate their proficiency only after having been trained to use the two identified strategies. In conclusion, the two identified strategies were reliable in the elimination of the challenges faced by the L2 learners when attempting to learn the inflection in this regard.

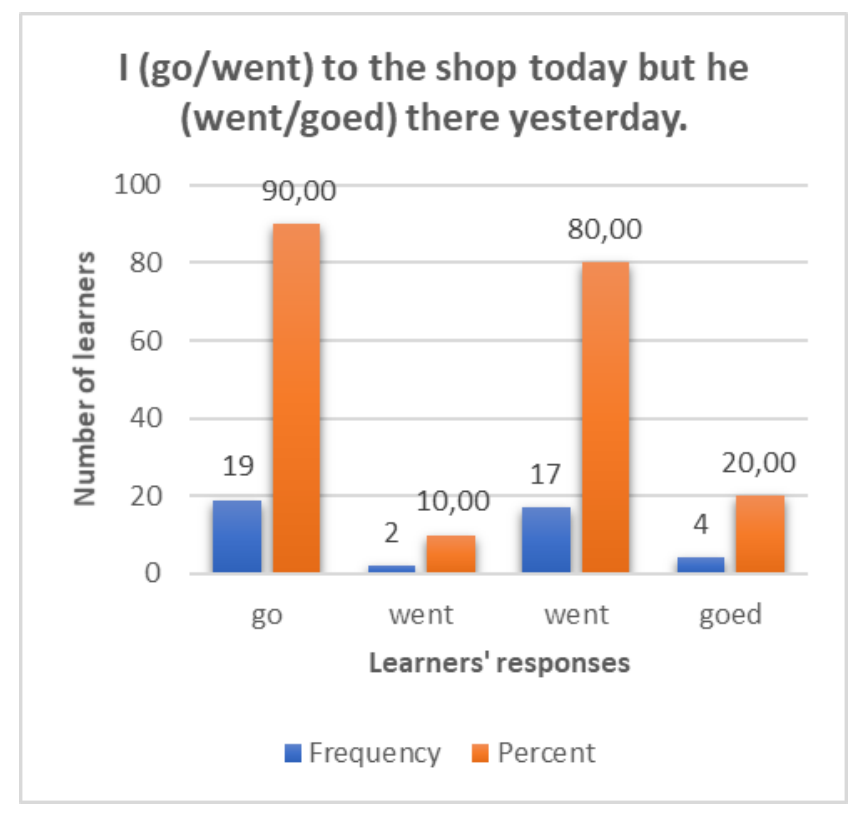

Fig. 1 Suppletion 
It is pleasing to note that 19 respondents amounting to $90 \%$ were aware that the simple present tense form of the verb 'go' had to be used in the first option. Furthermore, 17 respondents amounting to $80 \%$ were also mindful that in the second option, the past simple form of the verb 'went' could indicate their expertise in the inflection of an irregular verb in this context. In this situation, it is therefore evident that these respondents were conscious of the use of the suppletion principle as one mechanism of forming the irregular form of the verbs in the past simple tense. This suggests that after having learnt the strategies for mastering the irregular verb inflection such as the 'grouping of common irregular verbs', and the 'learning of irregular verbs in sentences', respondents realised the inflection of irregular verbs in the past simple tense. This finding is unrelated to Rahmawati's (2019) and Mouri's (2020) suggestion that learners face challenges in the inflection of irregular verbs in the past simple tense.

Respondents never realised that the complete stem /go-/ must be replaced by a different stem to effect a total change within a paradigm (Helmie \& Hum, 2012). The formed morpheme has a morphological relationship with the two phonologically unrelated realisations in 'am', 'is', 'are', and their past forms. They also knew that the root morpheme must not be replaced by a phonologically unrelated form to designate grammatical contrast and that the replacement of one stem with another could be done. Besides the allomorph, having no phonological similarity to the other allomorphs, must also not be fashioned.

However, only 2 respondents amounting to $10 \%$ were unaware of the fact that the variable 'went', in the first option, could not be the desired option as they were dealing with the present simple tense form of the verb. They might have been confusing the rule about the past simple form of the verb with the present simple tense. This rule states that when forming the past simple tense, verbs must be changed into their past simple forms. Moreover, 4 respondents amounting to $20 \%$ were also unaware of the fact that the variable *'goed' is ungrammatical and could not prove their anticipated competence in the inflection of irregular verbs in the past simple tense. The respondents, in this context, might have overgeneralised the use of the -ed ending through the addition of the verb 'go' and formed *'goed'.

Nevertheless, only the minority of the respondents, approximately 2 and 3, faced difficulties in the inflection of irregular verbs in the past simple tense. They could not realise the morphological processes involving the stem's replacement with another stem in the past simple tense (Majeed, 2018) although they had learnt how to group common irregular verbs and learnt them in sentences. The respondents might have been confused by the rule regarding the addition of the suffix '-ed' in the past simple tense. It can be construed that the respondents could not show their expertise in using the irregular verb 'go' and the inflection of 'went'. They could still select the ungrammatical word *'goed' and 'went' unnecessarily for an answer. The targeted strategies improved the learning of irregular verbs in the past simple tense although the minority of the learners showed poor mastery.

\section{CONCLUSIONS}

The Grade 10 EFAL learners' strategies for past simple tense irregular verbs inflection mastery are important tools for communication. From the findings of this research paper dealing with the questionnaires involved in the strategies for learning irregular verb inflection in the past simple tense, therefore, the key conclusions are:

Competence in the inflection of irregular verb inflection in the past simple tense cannot be disregarded. The two identified strategies, namely: the grouping of common irregular verbs and the learning of irregular verbs in sentences can bring a major improvement in the inflection pf irregular verb inflection. Understanding the use of the suppletion principle and the terminal consonants phoneme changes is a requirement for learning irregular verb inflection in the past simple tense.

In line with the conclusions mentioned in the preceding paragraph, the next suggestions are: Encouraged learners to practise the grouping of common irregular verbs and the learning of irregular verbs in sentences strategies. Workshop English teachers frequently on the inflection of irregular verbs. Urge researchers to carry further studies on the inflection of irregular verbs,

incorporate strategies for the teaching and the learning of irregular verb inflection in the past simple tense into the school syllabus.

\section{REFERENCES}

Abuhamda, E., Bsharat, T. R. A. \& Ismail, I. A. (2021). Understanding quantitative and qualitative research methods: A theoretical perspective of young researchers. International Journal of Research, 8(2):71-87.

Aryal, S. (2019). Questionnaire method of data collection. Microbe Notes. Available online at:https://microbenotes.com/questionnaire-methodof-data-collection/[Accessed on 18 August 2021].

Author. (2019).

Atlas Language School. (2020). MacMillan verb wheel game. Available from Espresso English. [Accessed: 29 May 2021].

Bala, K. E. I. (2017). Sampling and sampling methods. Biometrics \& Biostatistics International Journal, 5(6):215-217.

Canale, M. \& Swain, M. (1980). Theoretical bases of communicative approaches to second language teaching and testing. In Allen, R. N., Spolsky, B. \& H. G. Widdowson (Eds), Applied linguistics. London: British Council, 1(1):1-47.

Chomsky, N. (1965). Aspects of the theory of syntax. Cambridge: The M. I. T. Press.

CreswelL, J. W. (2014). Research design: qualitative, quantitative, and mixed methods approach. Thousand Oaks: SAGE Publications. 
Deibler, S. (2012). Semantically implied irregular inflection. International Social Science Review, 87(1/2):35-46.

Denham, K. \& Lobeck, A. (2013). Linguistics for everyone: An introduction. (rev. 2nd ed.). Boston: Cengage.

EngVid. (2021). Learn English for free. Common Irregular verbs (grouped). Available from www.engVid.com [Accessed: 15 June 2021].

Gazu, K. (2020). English as second language students' strategies when reading and writing about literary texts: Some ethical considerations. Per Linguam, 36(2):16-27.

Helmie, J. \& Hum, S. S. M. (2012). Internal change, suppletion and reduplication in English: A Study of morphosemantic process. Journal of Aliena Bahasa, Santra, dan Pengajarannya, 1(2):97-200.

Idek, S. \& Fong, L. L. (2015). The use of consciousnessraising techniques in teaching the verb 'be' to students of vocational colleges. Procedia - Social and Behavioral Sciences, p. 208:111-121.

Lediga, M. \& Ngoepe, I. J. (2020). Exploring the effective use of mobile devices by previously disadvantaged English language student educators the constructivist way. Per Linguam, 36(2):104-125.

Majeed, M. N. (2018). Writing difficulties: An investigation of irregular morpheme errors among the students in the South-Eastern University of Sri Lanka. International symposium, pp.953-963.

Mouri, C. (2020). Summarizing as a strategy to English grammar and writing skills: The case study of the First-year LMD learners at the Algerian university Dr. Tahar Moulay-Saida. Arab World English Journal, 11(2):21.

Naser, M. (2017). The use of irregular cases by English language and literature students at the University of Tabuk. British journal of sociology, 16(2):103.

National Curriculum Statement Grades R-12. (2012). English First Additional Language Grades 10-12. Pretoria: Department of Basic Education, pp.1-91.

Nordquis, T. R. (2017). Grammar in English definition and examples. Glossary of grammatical and rhetorical terms. Available from http:/www.googlescholar.com [Accessed: 26 March 2021].

Odetallah, R. F. (2013). Teaching the regular and the irregular verbs through a cultural-based literary discourse in an ESL grammar classroom. Arab World English Journal,4(2):122-136.

Patterson, K., Lambdon, R. M. A, Hoges, J. R. \& Mcclellard, I. L. (2001). Deficits in irregular pasttense verb morphology associated with degraded semantic knowledge. Neuropsychologia, 39:709724.

Petty, R. E., Cacioppo, J. T., Strathman, A. J. \& Priester, I. R. (2005). To think or not to think. Persuasion: Psychological insights and perspectives, 81, p.116.
Rahmawati, U. (2019). An analysis of the difficulties faced by the students in learning simple past tense in the eighth grade of SMP N 1 Baki in the academic year of 2018/2019. (Bachelor of Education dissertation). Department of English Education. Indonesia: Muhammadiyah University of Surakarta.

Ramscar, M. (2002). The role of meaning in inflection: Why the past tense does not require a rule. Cognitive Psychology, 45(1):45-94.

Rundell, M. (2014). Macmillan English Dictionary: The end of print? Slovenščina 2.0, 2 (2):1-14.

Rosydah, E. C. (2018). Improving student's mastery of irregular verb by using memrise application at the tenth grade of Man Sidoarjo. Perpustkaan, Surabaya Sunan Ampel State Islamic: Kentarian Agama Universitas Islam Negeri.

Tatik Sutarti, T. (2017). Efforts to Increase Students Reading Interest on Educational Reference Through Classical Guidance and Counseling Experiential Learning Model. Journal of Education, Teaching and Learning, 2(1): 59-64, p-ISSN: $2477-5924 e$ ISSN: $2477-4878$.

Zaia, S. (2015). Regular and irregular verbs. Graduate writing lab. Yale Center for Teaching and Learning. Available

from https://poorvucenter.yale.edu/sites/default/files/.../re gular_and_irreg ular_verbs1. pdf [Accessed:16 March 2021]. 